\title{
Final Report of the Static Bonding Team* Pantex Plant, Amarillo, Texas
}

Prepared by

R. D. Jones, K. C. Chen, and S. W. Holmes Electromagnetic Analysis and Test Department

Sandia National Laboratories Albuquerque, New Mexico 87185-0865

"Battelle - Lawrence Livermore National Laboratory - Mason \& Hanger - Sllas Mason Co., Inc. - Sandia National Laboratories 
İssued by Sandia National Laboratories, operated for the United States Department of Energy by Sandia Corporation.

NOTICE: This report was prepared as an account of work sponsored by an agency of the United States Government. Neither the United States Government nor any agency thereof, nor any of their employees, nor any of their contractors, subcontractors, or their employees, makes any warranty, express or implied, or assumes any legal liability or responsibility for the accuracy, complcteness, or usefulness of any information, apparatus, product, or process disclosed, or represents that its use would not infringe privately owned rights. Reference herein to any specific commercial product, process, or service by trade name, trademark, manufacturer, or otherwise, does not necessarily constitute or imply its endorsement, recommendation, or favoring by the United States Government, any agency thereof or any of their contractors or subcontractors. The views and opinions expressed herein do not necessarily state or reflect those of the United States Government, any agency thereof or any of their contractors. 
SAND93-2502

Distribution

Unlimited Release

Printed December 1993

Category UC-906

\title{
Final Report of the Static Bonding Team Pantex Plant, Amarillo, Texas
}

\author{
Prepared by \\ R. D. Jones, K. C. Chen, and S. W. Holmes \\ Electromagnetic Analysis and Test Department \\ Sandia National Laboratories \\ Albuquerque, New Mexico 87185-0865 \\ for \\ Battelle \\ Lawrence Livermore National Laboratory \\ Mason \& Hanger - Silas Mason, Inc. \\ Sandia National Laboratories
}

\begin{abstract}
The integrity of the electrostatic bonding procedures used to equilibrate operating technicians and weapon components was questioned during the course of the quality evaluation assessments of the W70, W68, and B57 dismantlement programs. A multi-disciplined, interlaboratory team was convened on an ad hoc basis to resolve certain static bonding issues. The accomplishments of this team in upgrading the integrity of the bonding process include recommendations on the proper use of wrist straps, training of technicians in their use, and procedures to reduce accumulation of static charge on components during routine handling operations.
\end{abstract}
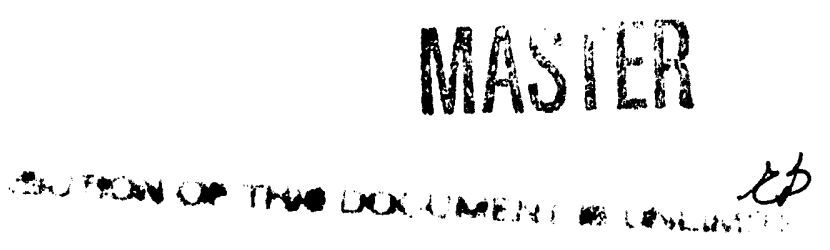


$$
4
$$




\section{Contents}

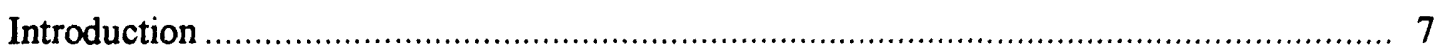

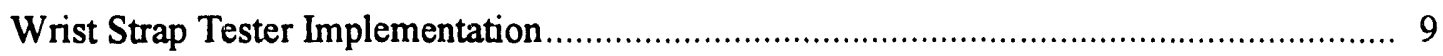

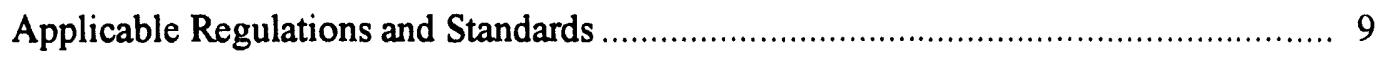

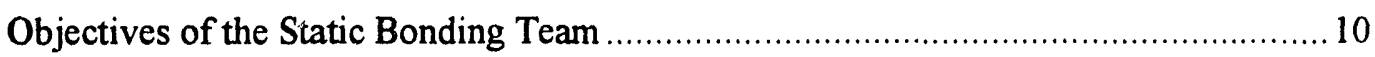

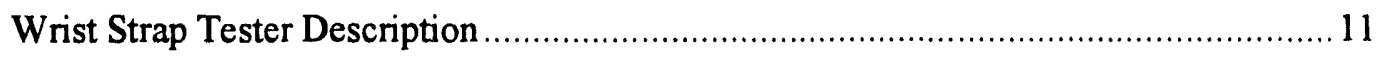

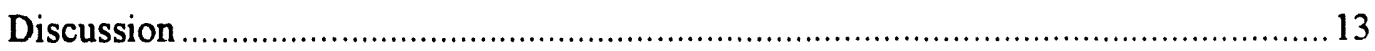

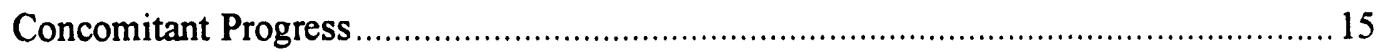

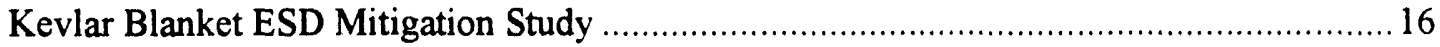

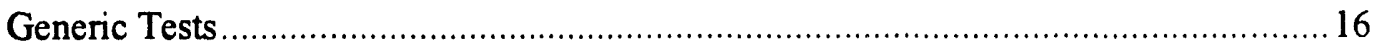

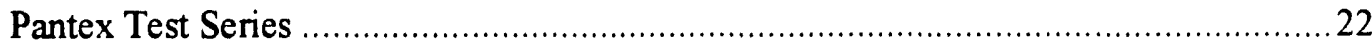

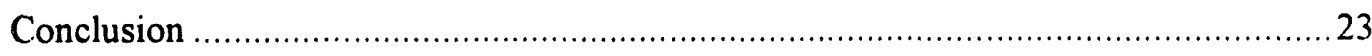

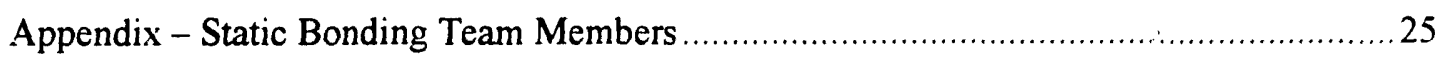

\section{Illustrations}

1 Cylindrical generic shape and electrostatic fieldmeter used in Kevlar ${ }^{\circledR}$ ESD charging studies. 17

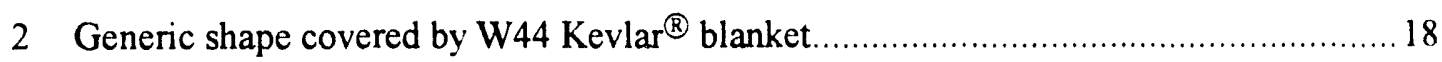

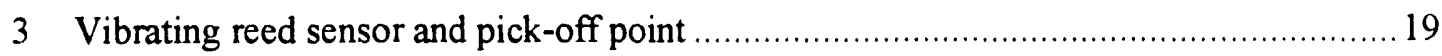

Table

1 STATICO $($ Specifications 


\section{Final Report of the Static Bonding Team Pantex Plant Amarillo, Texas}

\section{Introduction}

Most nuclear weapons contain components that are sensitive to electrostatic discharge (ESD). To prevent activation or damage of these components with subsequent risk to operating technicians, to plant safety, or compromise of weapon reliability, conducting wrist straps are used to electrically bond the technicians to the weapon when handling ESD-sensitive systems.

During the course of the Quality Evaluation for Dismantlement (QED) for the W70, W68, and B57 dismantling programs, some observers questioned whether the wrist strip and cable used to connect the strap to the warhead were tested and evaluated frequently enough. At the time, the Pantex preventive maintenance program (PM) required that the wrist strap be tested and certified quarterly. As a consequence, the QED final report included a requirement that Pantex study the feasibility of providing wrist strap testers in bays and cells to promote more frequent testing. At issue here is the impact of the use of a wrist strap tester on operations in the bays and cells, and the effectiveness of a wrist strap tester in detecting impaired static bonding.

Preliminary discussions on procedures required to ensure integrity of the bonding system were held at SNL, Livermore, on December 8, 1992. Representatives from Organizations 5355, 5362, 5366, and 2753 were present. Ad hoc discussions were resumed at Pantex on December 16. Participants included representatives from these SNL organizations as well as representatives from Mason \& Hanger and Battelle." Between January and April, meetings of this group, which reconvened as the Static Bonding Team, were held almost biweekly and the membership was increased to include a number of specialists who contributed substantially to an understanding of the problem. The last meeting was held on July 28, 1993; the Team charter expired on September 30,1993

This memorandum reports the accomplishments of the Static Bonding Team in upgrading the integrity of the bonding process. Although the Team was unable to identify a viable wrist strap test regimen, substantial progress has been made in quality control of wrist strap maintenance and utilization. Other ESD issues, for example, the Kevlar ${ }^{\circledR}$ security blanket ESD problem (a

\footnotetext{
* A list of participants and their affiliations is given in the Appendix.
} 
unit becomes charged to a high voltage when the blanket is removed), have been addressed by the Team. A report on the progress achieved in this matter is given in this report.

Several actions have been initiated to enhance the bonding operations. These actions include increased user awareness and specific identification of the various available wrist straps. A training film emphasizing the importance of conscientious bonding is in production. By increasing user awareness, the Production Technicians know why the bonding operations are necessary. 


\section{Wrist Strap Tester Implementation}

\section{Applicable Regulations and Standards}

Persons handling electrostatic-sensitive explosive devices should be bonded to these devices; that is, they should keep the electrical potential at the same level between themselves, the components, and the next assembly. Detailed guidance on the bonding implementation have been provided by cognizant safety agencies. From the outset, it was clear that the bonding process currently in use at Pantex is in compliance with paragraph 7.5e of the DOE Explosive Safety Manual if "ground" is interpreted to be the outer case of the warhead under assembly or disassembly: 1

Conductive wristbands shall not exceed a resistance between the wearer and ground of $1,200,000 \mathrm{ohms}$. This resistance shall be measured with a suitability calibrated Ohmmeter. Wristbands shall be of a design that maintains electrical contact with the wearer when used. Wristbands shall be of a design that maintains electrical contact with the wearer.

The use of the verb "shall" means that the requirement must be followed unless written authority for deviation is granted as an exemption by the DOE. The frequency at which the resistance "shall" be measured is not given, specifically. However, according to paragraph 7.3 of the manual "grounding systems shall be tested for electrical resistance and continuity . . . at intervals to be locally determined." Because the wrist straps are assigned commercial tooling numbers and are subject to a preventive maintenance program following a schedule approved by Pantex safety organizations, presumably DOE requirements are satisfied.

In addition, it might appear that rules apply which are set forth by the Occupational Safety and Health Administration (OSHA) in the Code of Federal Regulations (CFR) Title 29, Part 1910. Although frequency of testing is not specifically addressed, DoD 4145.26 is cited as a "Related Publication." Of particular relevance is Chapter 13, Safety Standards for Specific Explosives Materials and Operations. Paragraph 3 of Section 3, Handling Low'-Energy Initiators, states that resistance readings, including that of the operator, must be taken once daily. (It should be noted that safety standards listed as a "Related Publication" are enforceable in lieu of any'

1 DOE Explosives Safety Manual, DOE/EV/06194, Revision 6, U.S. Department of Energy'. Assistant Secretary for Environment, Safety, and Health, Office of Quality Programs, October 1991. 
applicable CFRs under Paragraph 5A1 of the Occupational Safety and Health Act.) However, it can be argued quite reasonably that because the DoD takes exception to this standard in the case of nuclear explosives, operational procedures at Pantex should also not be bound by this particular requirement. For example, wrist straps are not used in Limited-Life Component Exchange (LLCE) operations by the military. Instead, "touch-off" procedures are enforced. The exception is authorized by a DoD directive which states that, "when contractual work is to be performed at DoD facilities Military Departments can apply their own selected...safety standards and procedures..."2.

In the final analysis the safety associated with any operation depends on the conscientious observance by the operating technician of procedures written by the project engineers. The arguments presented in this memorandum should be adequate documentation of the procedures adopted in case of an OSHA or DOE audit. However, to comply with the Team charter it is proper to provide either a wrist strap tester system or give adequate justification for not doing so This is addressed next.

\section{Objectives of the Static Bonding Team}

One of the principal objectives of the Static Bonding Team was to implement by April 15, 1993, a Wrist Strap Tester system capable of checking the integrity of the bonding system. Some restrictions were placed on the test system:

1. It must be battery-operated and the maximum battery voltage permitted in the nuclear explosive area (NEA) is $9 \mathrm{~V}$.

2. Its impact on established dismantlement procedures must be minimal.

3. It must be reliable and its operation must be consistent.

Procurement, evaluation, and preliminary assessment of the efficacy of five candidate commercial test systems was completed by mid-January. One system was selected by the Team and ten units were obtained for procedural evaluations. However, what initially appeared to be a simple implementation turned out to be exceedingly complicated. A number of conflicting issues, mechanical as well as electrical, had to be resolved. Not the least of these were conflicting test

2 DoD Contractors' Safety Requirements for Ammunition and Explosives (Incorporating Change 1, 11/8/90) DoDD 4145.26 CE-01 RPT, Issue Date 19 July 85. 
procedures conforming to both DoD (i.e., OSHA) and industry standards. It soon became evident that a resolution of the problems would not be possible by April 15.

\section{Wrist Strap Tester Description}

The wrist strap tester selected was modified by the manufacturer to show clearly whether or not the resistance of the strap system, including the wearer, is at least $270 \mathrm{k} \Omega$ and not more than $10 \mathrm{M} \Omega .^{3}$ If the system is not within this range a "FAIL" indicator lamp will glow; a green "PASS" lamp indicates that the resistance of the strap system is within these limits. It is desirable that the dynamic range of the tester be as great as possible. The industry standard for the upper limit is $10 \mathrm{M} \Omega$. From a safety standpoint (EED handling), a much larger resistance would be acceptable. For example, if the capacitance of the technician is taken to be $400 \mathrm{pF}$ (the maximum value assumed in the human ESD model) and the total bonding circuit resistance is $250 \mathrm{M} \Omega$, the e-folding time is only 0.1 second, a time interval too short for a significant manual operation.

Calibration of the tester was verified by the M\&H Metrology Department. However, trials of the complete system on a small sample population of production technicians indicated an unacceptable failure rate, that is, of two subjects using the same wrist strap and tester, one passed, the other failed. The anomaly can be attributed to variability in the contact resistance across the skin-cuff interface. Contact resistance is determined by the physical and electrical surface characteristics of the cuff, the texture and dryness of the worker's skin, the amount of interfering hair, and most predominantly, how snugly the cuff fits the wrist.

The wrist strap used at Pantex is a Legge System Wristat ${ }^{\circledR}$ Model 2506. ${ }^{4}$ The skin-cuff interface is made by the means of a postage-stamp-size aluminum plate that is held firmly against the skin by means of a flexible, insulating fabric strap. Contact to the unit under disassembly is made by means of a standard copper wire cable terminated at one end by a snap fastener and at the other by an alligator or bull-dog (Mueller) clip; the $270-\mathrm{k} \Omega$ resistor is encapsulated in the wire. Resistance of the cuff-skin interface, presumably, would be a function

3 The wrist strap bonding system used at Pantex includes a series resistance of $270 \mathrm{k} \Omega$ to protect the wearer from dangerous levels of current flow from inadvertent interception of housc electrical service. (A current exceeding $1 \mathrm{~mA}$ is considered dangerous.)

4 Walter G. LEGGE Company, Inc., Static Control Division, 444 Central Avenue, P.O. Box 591, Peekskill, NY 10566. 
of the position of the aluminum electrode with respect to the wrist, that is, inside or outside in addition to the parameters noted above.

A check of the resistance of the skin-cuff interface, including the 270-k $\Omega$ series resistance, was performed by Team representatives on thirteen production technicians. Interface resistance measurements were made on both left and right wrists and also on either side of the wrists of the subjects. On the average, there was essentially no difference between measurements at corresponding locations on either wrist of individual subjects. That is, effective bonding would be expected irrespective of left- or right-hand preference of an individual technician. However, the resistance of the interface was about an order of magnitude larger if contact was made on the outside of the wrist. In fact, for one subject, the difference in contact resistance on either side of the same wrist was three orders of magnitude. From these measurements, it can be concluded that the preferred point of contact is on the inside when using the Legge strap.

The variability in resistance of the skin-cuff interface observed in the Pantex study can be attributed, at least partly, to biogalvanism..$^{5}$ The responsible mechanism is the "human battery" effect often demonstrated at science fairs: by simply grasping two electrodes composed of different metals, a variable current of up to $0.5 \mathrm{~mA}$ can flow between the electrodes, for example, in a copper-zinc system. Existence of this current could effect significantly the measurements in the Pantex study and would account for individual variability in the skin-cuff interface resistance. To overcome human battery effects, wrist strap measurements should be made using monometallic systems, preferably stainless steel. This could be done simply by using two identical wrist straps on each wrist. In addition, the voltage source used for interface resistance measurements should be at least $9 \mathrm{~V}$. Although a higher voltage source would be more effective in reducing variation in resistance measurements between subjects by masking the biogalvanic effects responsible for variation, the highest voltage allowed in the NEA is $9 \mathrm{~V}$ to be exempt from the Master Equipment List (MEL) requirements.

${ }_{5}^{5}$ Huntsman, James R. and Donald M. Yenni, Jr., Test Methods for Static Control Products, EOS/ESD Symposium, Orlando, FL, 1982. 


\section{Discussion}

It has been observed that occasionally the wrist strap cuff becomes disconnected from the bonding wire. This should not be construed as a fault. Section A.1.4 of EOS/ESD-SI standard6 on wrist straps states:

Under no circumstances should an individual be tethered to a work position in a fashion which might prevent easy and rapid departure from the vicinity in the event of an emergency.

Accordingly, the breakaway considered to be a fault is intentional. In fact, Section 4.1 .6 of the same standard states in regard to breakaway force:

With the ground lead connected to the cuff in the normal manner and the cuff placed on a person's wrist, at least 1 pound but not more than 5 pounds of pull force applied to the ground lead in the normal disconnect direction shall be required to cause separation from the cuff.

Every wrist strap, irrespective of manufacture, will conform to this specification.

On the basis of the data obtained in the skin-resistivity study it was the consensus of the Team that at least for the present, the wrist strap tester considered for implementation should not be used because many false alarms would be produced that would not affect safe handling of the EED. However, the DoD regulation cited on page 2 cautions that the required daily check might be difficult to administer:

"Special contact creams may be used to decrease the resistance to the required value."

The required value is $25 \mathrm{k} \Omega$, an order of magnitude less than the current-limiting resistance used in the bonding leads. If it is necessary to be in compliance with the DoD regulation, the check system must be a viable operation. Several options were investigated separately or in combination:

1. Delete the series resistances in the bonding leads.

2. Replace the wrist strap.

3. Use static dissipative hand lotion.

4. Redesign the tester.

5. Replace tester with a continuous bonding system monitor.

These issues are addressed separately in the following discussion.

${ }^{6}$ Electrical Over Stress/Electro Static Discharge. 
1. Delete the series resistances in the bonding leads. A current-limiting resistor is typically incorporated in series with the wrist strap grounding circuit. The purpose is to protect the user from electrical current that might pass through the ground lead to the wrist in the event of inadvertent contact of the user with hazardous voltage sources with high current capabilities. The EOS/ESD industry standard resistance value is $1.0 \mathrm{M} \Omega$; however, DoD 4145.26 requires a resistance of $25 \mathrm{k} \Omega$. These standards are contradictory. Although there are few high-current high-voltage sources in the NEA (power tools are pneumatically driven), if the AC service is assumed to be $240 \mathrm{~V}$, the maximum current through the strap in the event of inadvertent contact will be $10 \mathrm{~mA}$, a potentially lethal value. Furthermore, because replacing existing ground leads would be inconvenient, it is recommended that the present bonding leads be retained. However, it would be prudent to officially document reasons for not complying with DoD 4145.26. The arguments presented above on e-folding discharge time should be sufficient.

2. Replace the wrist strap. Although it is possible to increase the conducting area of the wrist strap thereby decreasing the large variability in cuff-skin interface resistance noted in the Pantex study, alternative strap designs were considered. A number of vendors supply Speidel ${ }^{\circledR}$ expandable stainless steel wrist bands. Some representative samples were obtained and evaluated These were judged to be less robust than those currently in use, moreover, a "one-size-fits-all" model was not available.

3. Use static dissipative hand lotion. Using static dissipative hand lotions is a viable but undesirable option: plant procedures would have to be rewritten, and the lotions could contaminate tools, components, or assemblies. At best, lotions would only ensure proper operation of the wrist strap tester and would not substantially enhance operational safety.

4. Redesign tester. Tester modifications would require additional data on cuff-skin interface resistance variability. One simple modification considered would be to replace the touch plate on the candidate checker with a plate having the same chemical composition as the wrist strap material. Advantages accruing from use of a tester could not be demonstrated conclusively. Therefore, tester redesign became moot.

5. Replace tester with a continuous bonding system monitor. The concept of wrist strap assessment performed once per shift could be discarded in favor of a continuous bonding monitor. Two candidate systems were procured. Each are capacitive relays that provide a bond to the work of interest. In principle, the operator serves as a capacitive arm of a bridge network. So long as the operator appears to be a capacitor whose value is greater than, say $100 \mathrm{pF}$, the device is quiescent. Otherwise, it alarms both audibly and visually. Generally, studies show a variability 
in body capacity between 100 and $400 \mathrm{pF}$. Performance may be more consistent than that observed with the simple wrist strap tester. Cost of continuous monitors is comparable to that of the testers. However, continuous rather than intermittent power must be supplied and the reliability problem could be exacerbated.

Whether or not any of these options are exercised, the Team's original observation that the wrist strap currently in use is very robust and provides adequate bonding. Insertion of additional complexity into the bonding process was deemed inadvisable. The rationale for not implementing a wrist strap tester in the dismantlement program is that the false alarm rate would negate any benefits derived from testing those wrist straps now in use at the Pantex Plant.

\section{Concomitant Progress}

Although the bonding Team has not been able to implement a wrist-strap test program, the quality of the bonding process has been significantly enhanced. A notable accomplishment was the promotion of a user awareness education program for Production Technicians. Portions of a training film produced by the SNL Military Liaison Department for the US Navy were combined with similar segments from relevant Pantex videos to produce a pilot training film that emphasizes the importance of static bonding. Production of additional footage emphasizing Pantex procedures has been scheduled. A series of "stand-up" meetings in conjunction with the film have proved to be very effective in promoting ESD awareness.

Quality control of the wrist straps has been improved by assigning commercial tooling numbers to each type of strap. Each type will have a Support Data Sheet (SDS) which will have additional information for the Preventative Maintenance (PM) program.

Also significant was the development by the $\mathrm{M} \& \mathrm{H}$ Tooling Department of a " $\mathrm{C}$ " clamp that provides a specific bonding point for the wrist strap lead. The clamp is so configured that a Mueller clip cannot become unattached inadvertently. This improvement is specific to the B57 program 


\section{Kevlar Blanket ESD Mitigation Study}

The study of the Kevlar $(B)$ blanket problem was motivated by technicians in Nuclear Explosive Areas who reported electrical shocks from the aluminum containers used with the W70 during interplant transfer. During transfer, the W70 - surrounded by a cylindrical aluminum standoff - is moved about the plant on a dolly. The stand-off, in turn, is covered by a Kevlar $\circledast$ blanket which, when removed, induces a charge on the standoff. In a cursory preliminary assessment, this procedure was replicated in the training area and the potential of the standoff was measured at $8 \mathrm{kV}$.

The disassembly procedure was observed and it was determined that the charge transferred to the W70 would not be hazardous. The detonators and associated wiring are made inaccessible by a specially designed cover (Shay cover). However, after the Kevlar $ß$ blanket is removed, the technician can receive an unpleasant electrical shock as the charge on the standoff discharges to ground through the technician. Although this is not a physical or safety hazard, it is a psychological factor that is not insignificant in a stressful situation.

The intensity of the shock felt by the operator can be reduced considerably by inserting a large series resistor between the operator and the standoff. The PVC gloves commonly used in the Nuclear Explosive Areas should serve well as a current limiting resistor. ${ }^{7}$ This was verified by test and the Nuclear Explosive Safety Department recommended that the appropriate W70 O\&I Standards be annotated with directions to use the PVC gloves while removing the Kevlar $\mathbb{B}$ blanket.

The relative humidity of the training bay where the preliminary tests were held is uncontrolled, and because humidity has a marked influence on the efficiency of the charging process, it was recognized that additional tests should be conducted in Nuclear Explosive Areas. In the following, results of additional tests in low humidity environments and discussions and recommendations are made on steps that can be taken to further mitigate the ESD mechanisms.

\section{Generic Tests}

Because other weapon programs use Kevlar $(\mathbb{B}$ blankets, an effort was made to investigate the basic charging mechanisms associated with the use of blankets. Two obsolescent blankets used

7 Using techniques to be described, the measured surface resistivity of the standard green Pantex glove is $80 \mathrm{G} \Omega$ per square. 
with the W44 program were provided by the Mason \& Hanger Tooling Department for use in the study. Efforts to procure the corresponding W44 shipping containers were unsuccessful and so two generic shapes, one cylindrical and one rectangular, were fabricated from sheet aluminum.

Figure 1 shows the basic laboratory test setup with the cylindrical shape attached to a B57 dolly; Figure 2 shows a W44 blanket covering the cylindrical shape. Visible in both figures is the Monroe Model 245 electrostatic fieldmeter used to measure the charge acquired when the blanket was removed. Figure 3 shows the vibrating reed sensor associated with the fieldmeter. The sensor is positioned $1 \mathrm{~cm}$ from the head of a screw electrically connected to the cylinder. As charge increased on the surface of the cylinder, the electrostatic field in the vicinity also increased proportionately. The fieldmeter provided an output signal proportional to the surface charge accumulation while making no physical contact with the cylinder. A copper pipe used to supply cooling water to the laboratory power supplies served as ground reference for the fieldmeter.

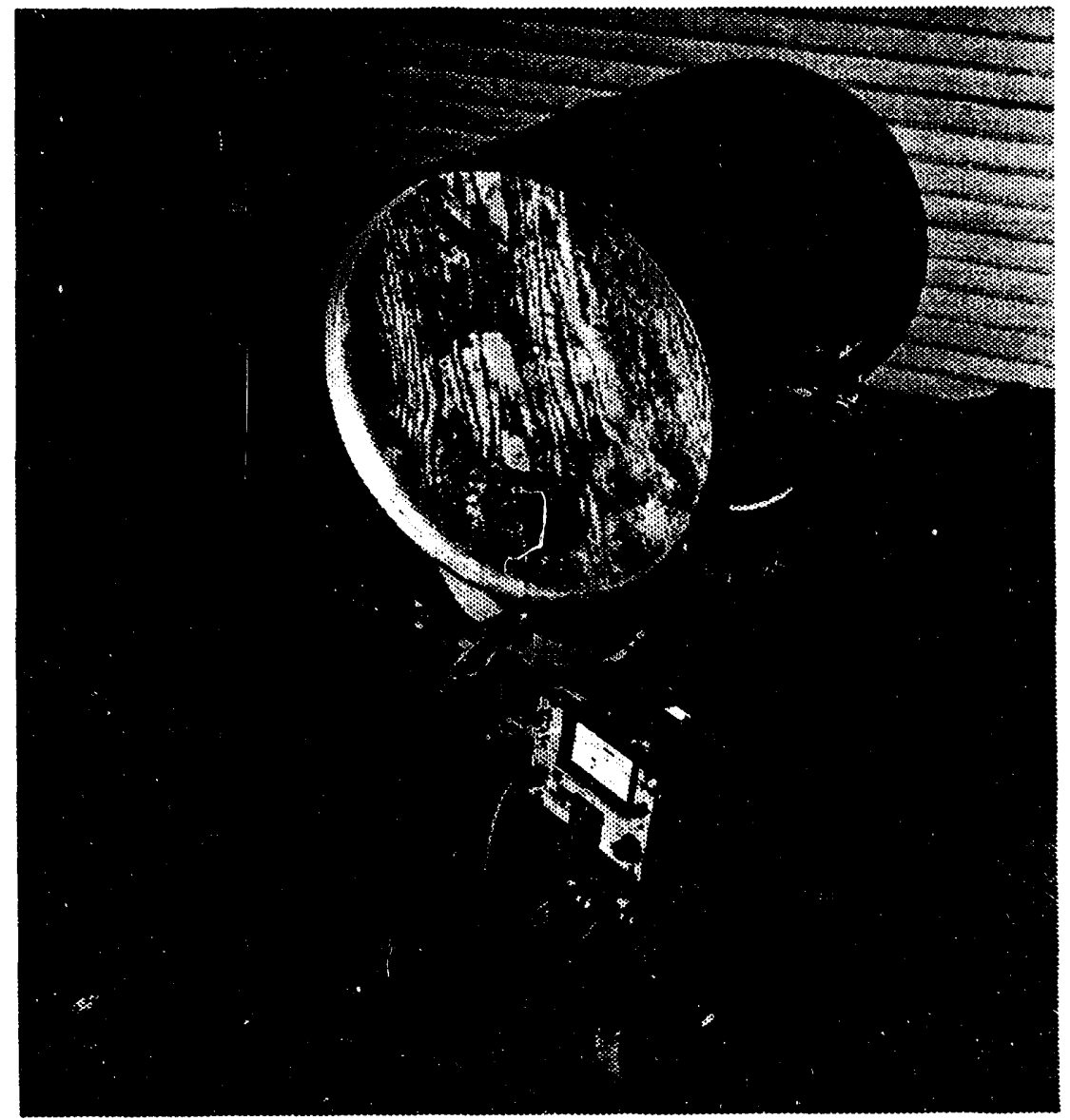

Figure 1. Cylindrical generic shape and electrostatic fieldmeter used in Kevlar@ ESD charging studies 


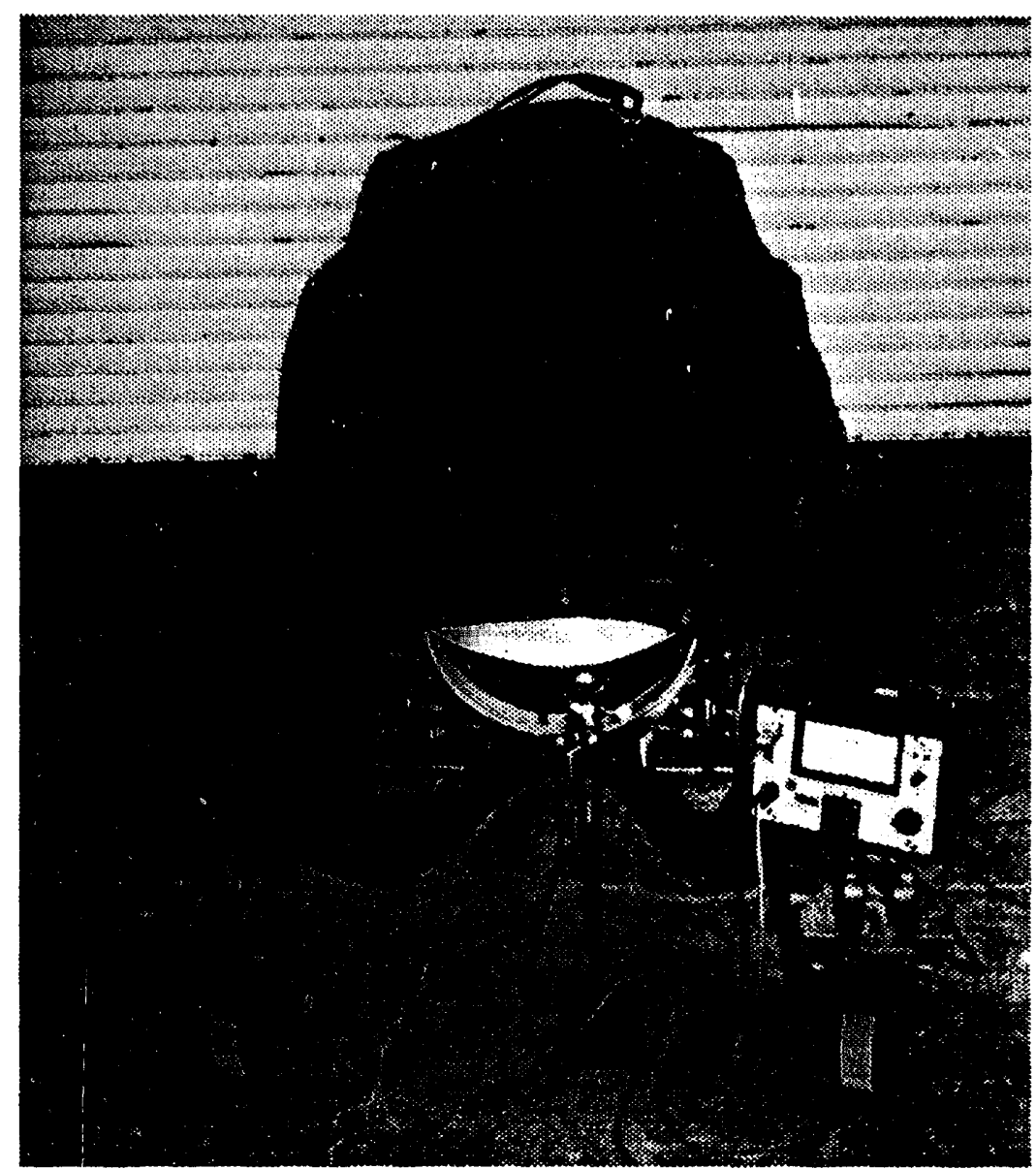

Figure 2. Generic shape covered by W44 Kevlarß blanket

A number of tests were conducted using two subjects to remove the blanket from the generic shape. Voltages generated on the shape varied from 4 to $10 \mathrm{kV}$ depending inversely on the ambient relative humidity, that is, voltage increased with decreasing relative humidity. Furthermore, it is the equilibrium humidity that is significant. If a blanket is stored for a period of several hours in an area in which the relative humidity is high, say $70 \%$, and is then moved to an area where the relative humidity is low, say $10 \%$, and the removal test is performed before equilibrium is reestablished, the charge accumulation is that which would be expected if the removal was made in the more humid area. In general, charge generation efficiency (ratio of electrical energy produced to frictional work expanded) is highest in a very low humidity environment assuming that the material of interest, in the present case the nylon lining of the blanket in contact without the metallic surface, assuming that the moisture adsorbed on the nylon is in equilibrium with the moisture in the environment. 


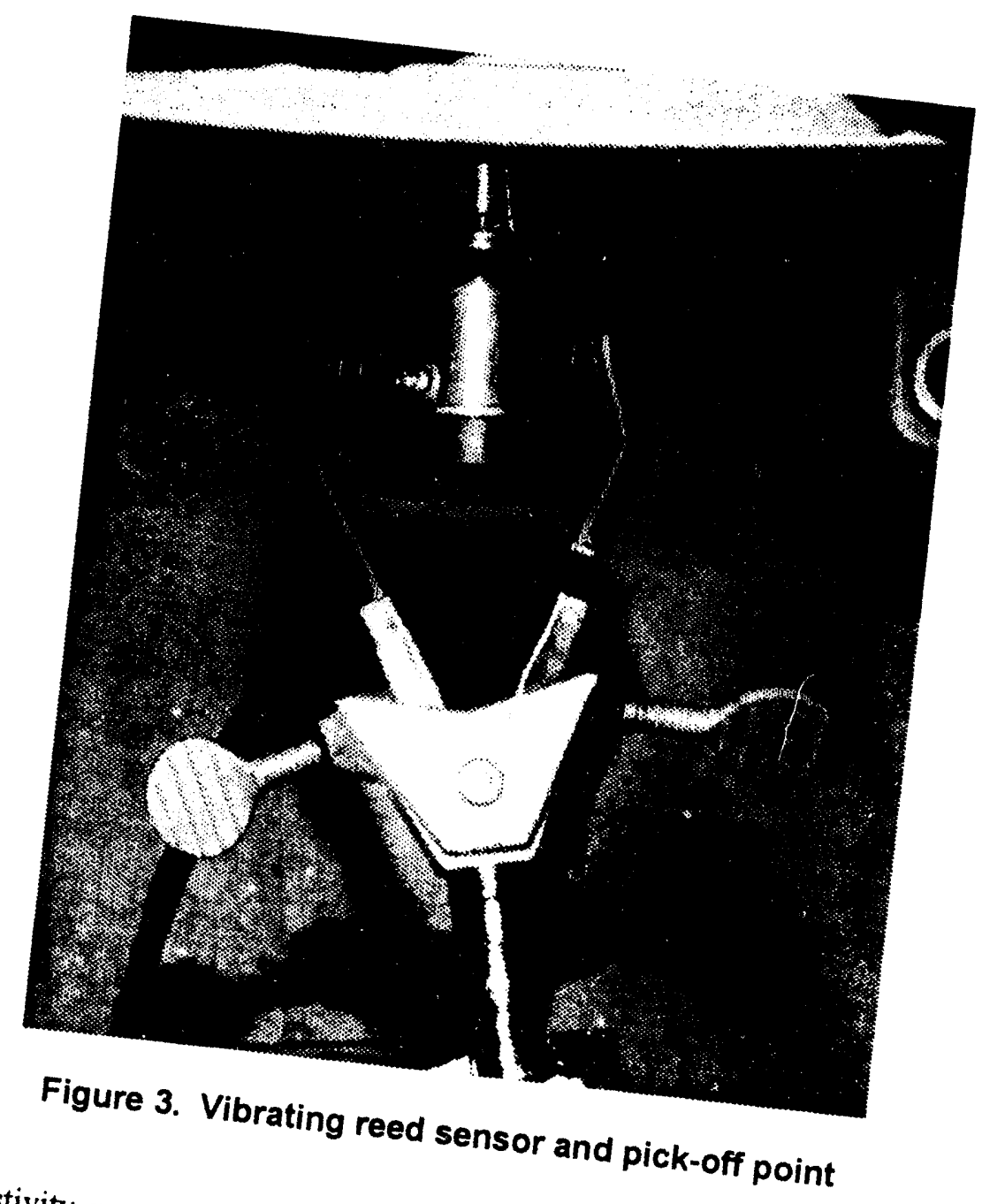

manufacturer, Armor of Americats were made on a lining sample provided by the blanket gradient parallel to the current along its surface to resity of a material is the ratio of the potential numerically equal to the surface resistance betwee current per unit width of the surface and is square. (The size of the square is immatetween two electrodes forming opposite sides of and a PROSTAT model PTB gohmmeter, PROSTAT model PRF-9 the test consisted of a using the EOS/ESD-DS IB-920 dual test bed. Surface and resistance 11 , concentric ring fixture factor of 10 estimates 11 -191 guidance. By multiplying these measurements were made ohms/square ${ }^{8}$ The ASTM obtained of the ASTM D257 equivalents (in ohms) by a surface resistivity of the nylon was greater than $1000 \mathrm{G} \Omega$ per square.

${ }^{8}$ American Society for Testing Materials 
Two different approaches were considered as feasible to reduce the charge generated by the nylon lining. Either the nylon can be replaced by a material which lowers surface resistivity or the nylon can be treated with one of the anti-stat compounds designed to lower surface resistivity. The former is permanent but expensive; the latter is inexpensive but the variation of surface resistivity with time and use is unknown.

In addition to decreasing the surface resistivity, the anti-static compounds, or surfactants are remarkably effective in reducing static charge buildup. Very little systematic research has been done to determine the anti-static mechanism, at least, little literature on the subject is available. Apparently, the anti-static properties are primarily due to the conductance of the surfactant which forms the interface between the fabric and the metallic surface. As the blanket moves, the nylon lining and the metal become equally and oppositely charged. The surfactant then acts as a leaky dielectric while separation occurs, during which dissipation of the charge occurs.

One surplus blanket was refurbished by Armor of America who replaced the conventional nylon lining with a laminated nylon fabric with suffused monofilament carbon threads. ${ }^{9}$ The material had a measured surface resistivity (ASTM) of $8 \mathrm{k} \Omega$ per square on the conducting side. This side should envelope the metallic container (standoff), or in this case, the generic shape. A flexible pigtail terminated on one end with a Mueller clip was attached to the conducting fabric by means of Scotch copper tape. The cost of the modification was about $\$ 400$ including labor and material.

In those situations in which nuclear safety is a critical issue, both blanket and operator would be bonded with the standoff. All three then would be at the same potential irrespective of humidity or mechanical actions of the operator. (It is still possible, however, for all three objects to acquire a small but measurable charge with respect to ground, i.e., an unbonded conducting object.)

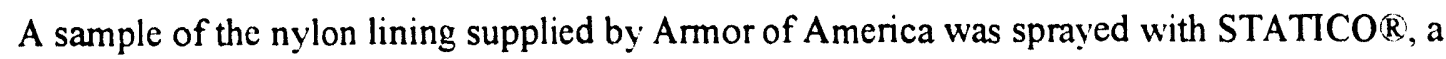
typical high-molecular weight, anti-stat surfactant also available from LEGGE. Technical specifications for this compound are given in Table 1. After spraying, the sample was sun-dried for two hours. The surface resistivity of the sample was reduced from $1000 \mathrm{G} \Omega$ to $50 \mathrm{M} \Omega$, that is, five orders of magnitude. Clearly, the anti-stat treatment is very effective in reducing surface resistivity.

${ }^{9}$ FSK anti ESD fabric available from LEGGE (Wristat Supplier). 
The unmodified blanket was hand-sprayed with anti-stat and surface resistivity measurements made at random locations on the blanket lining. Because the test bed could not be inserted without damaging the fabric, the standard EOS/ESD test could not be performed. However, resistivity measurements were made with the Kevlar itself serving as the test bed. The indicated surface resistivity varied from 1 to $10 \mathrm{G} \Omega$ per square.

Table 1. STATICO® Specifications

\begin{tabular}{|c|c|}
\hline Composition & $\begin{array}{l}\text { High molecular weight topical } \\
\text { anti-stat, water base }\end{array}$ \\
\hline Physical form & liquid \\
\hline Color & clear \\
\hline Flash point & none \\
\hline Explosion hazard & none \\
\hline Specific gravity - regular & 1000 a $60^{\circ} / 60^{\circ} \mathrm{F}$ \\
\hline Specific gravity - concentrate & 1002 a $60^{\circ} / 60^{\circ} \mathrm{F}$ \\
\hline Weight & $1 \mathrm{gal}=8.33 \mathrm{lb}$ \\
\hline Odor & none \\
\hline PH regular & 7.71 \\
\hline PH concentrate & 7.98 \\
\hline Concentrate dilution & $\begin{array}{l}1 \mathrm{oz} \text { to } 32 \mathrm{oz} . \\
4 \mathrm{oz} \text { to } 1 \mathrm{gal} .\end{array}$ \\
\hline $\begin{array}{r}\text { Static decay rate - seconds } \\
\text { MIL-B-81705-B } \\
\text { at relative humidity } 12 \%, 72^{\circ} \mathrm{F}\end{array}$ & $0.01 \mathrm{SEC} .+5.0 \mathrm{kV}$ \\
\hline $\begin{array}{r}\text { Surface resistivity test model } 801 \\
\text { probe ASTM D-257 } \\
\text { relative humidity } 12 \%, 72^{\circ} \mathrm{F}\end{array}$ & $4.6 \times 10^{9} \mathrm{ohm} / \mathrm{sq}$. inch \\
\hline
\end{tabular}


Charging tests on the generic body were repeated. Voltages acquired by the body decreased by a factor of from 10 to 100 , again depending on humidity. The results were sufficiently encouraging that a test series was scheduled at Pantex under conditions of controlled humidity.

\section{Pantex Test Series}

The first tests were held in Training Bay 3 where the ambient relative humidity and temperature were $70.3 \%$ and $71^{\circ} \mathrm{F}$, respectively. A PROSTAT model PFM-711A fieldmeter, referenced to the copper braid house ground, was used to measure the voltage attained by the W70 aluminum standoff. The resistance between standoff and its supporting dolly was 34 ohms. The capacitance of the s candoff with respect to the braid was $580 \mathrm{pF}$.

The test procedure consisted of the following sequence of steps:

- Ground standoff

- Zero adjust fieldmeter

- Install blanket

- Read standoff voltage

- Ground standoff

- Zero adjust fieldmeter

- Remove blanket

- Read standoff voltage

The above sequence was repeated five times with different subjects manipulating the blanket. Maximum observed voltages on blanket removal were $7.95,4.5,6.2,6.1$, and $2.0 \mathrm{kV}$. Installation voltages were roughly $25 \%$ of those observed when the blanket was removed. Variability can be attributed to differences in mechanical operations, for example, rate of blanket removal. The low voltages result from the high ambient relative humidity.

The blanket was then treated with STATICO $B$ and allowed to sun dry for 4 hours. The above test sequence was repeated and the maximum voltage attained by the standoff varied from 10 to

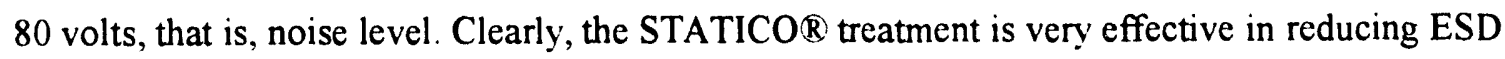
charging

The same test procedure was repeated in Bay 3, Building 12-99 where the ambient relative humidity and temperature were $10.2 \%$ and $73.9^{\circ} \mathrm{F}$, respectively. Two Mason \& Hanger technicians performed the blanket manipulations. During installation of the blanket, in three trials, the maximum standoff voltage was $2 \mathrm{kV}$. Maximum voltages attained during the first two removal trials were 5.1 and $17.5 \mathrm{kV}$. The next two trials resulted in standoff voltages in excess of $20 \mathrm{kV}$, i.e., beyond the calibrated range of the field meter. The blanket used in these tests was the one accompanying the unit when it arrived at Bay 3. 
The test was repeated using the treated blanket used in the Training Bay 3 tests. The maximum voltages attained by the unit as a result of removal varied from 80 to 140 volts, again showing that anti-stat treatment of the blanket is very effective in mitigating static charge buildup. The contrast between charging effectiveness of a treated and an untreated blanket is made more vivid if the comparison is based on the available energy which varies as voltage squared. For the examples considered here the energies are $3 \mu \mathrm{J}$ and $100 \mathrm{~mJ}$, respectively, for the treated and untreated blankets.

It is strongly recommended that all Kevlarß blankets be treated with a topical anti-stat, for example, STATICOß. The application can be completed in about 2 minutes using spray equipment. The cost of STATICO $B$ is a modest $\$ 18$ per gallon. Durability of the application is unknown; however, because this is a nuisance issue, the spray may be reapplied routinely by the operators as they perceive the need.

\section{Conclusion}

Althougn the Static Bonding Team was convened to address ESD problems associated specifically with the W70, W68, and B57 dismantlement programs, issues were identified that apply to all systems in either assembly or dismantlement. Development of generic approaches to ESD hazard mitigation appears to be feasible.

After an exhaustive study, the Team concluded that the incorporation of wrist strap testers in operational procedures will not lead to enhanced safety. However, in the process of this study several actions have been initiated to improve bonding procedures. The most important of these is increased emphasis on a training program oriented toward the impact of proper wrist strap usage on operational safety. Production of a training film illustrating these procedures is well under way.

As a result of the study several tooling adapters were developed to facilitate the selection of bonding points. By specifically associating these points with the various available wrist straps, process engineers are able to prescribe a particular wrist strap for a given operation thus ensuring that the appropriate clip is used in each bonding operation.

Static charging associated with operations involving Kevlar( $\mathbb{R}$ blankets will be eliminated Cost effective arrangements have been initiated for providing equipment required for ESD abatement procedures. 
. 
Appendix

Static Bonding Team Members

\begin{tabular}{lcl}
\hline \multicolumn{1}{c}{ Name } & Organization & \multicolumn{1}{c}{ Specialty } \\
\hline Ken Chen & SNL/NM & EM Analysis \& Test \\
Roger Coffey & M\&H/Pantex & Tester Design \\
Aaron Cormelius & M\&H/Pantex & Assembly Engineering \\
Eric Grose & SNL/NM & Human Factors \\
Joe Henard & M\&H/Pantex & Training \\
Dick Jones & SNL/NM & EM Analysis \& Test \\
Jeff Loerwald ${ }^{2}$ & M\&H/Pantex & Quality Systems \\
Tommy Morris & Battelle/Pantex & NES \\
Jane Parrish & M\&H/Pantex & Manufacturing Operations \\
Roy Pearson & SNL/CA & Systems Engineering \\
David Renteria & M\&H/Pantex & Evaluation Engineering \\
Norm Schneider & LLNL & Weapons Engineering \\
Karl Schuler & SNL/NM & Structural Mechanics \\
Duane Stoddard & M\&H/Pantex & Tooling \\
\hline 1 Chairman & & \\
\hline \hline
\end{tabular}




\section{Distribution}

1 United States Department of Energy, Headquarters

Attn: T. Goodwin, DP-251

1000 Independence Avenue S. W.

Washington, DC 20585

$4 \quad$ United States Department of Energy

Office of National Defense Programs

Attn: S. J. Guidice, OOW

H. T. Season, Jr., WPD

D. R. Baca, WPD

W. J. Baca, WPD

P. O. Box 5400

Albuquerque, NM 87185-5400

1 United States Department of Energy

Amarillo Area Office

Attn: G. W. Johnson

P. O. Box 30030

Amarillo, TX 79120

5 Los Alamos National Laboratory

Attn: G. G. Hill, WX-DO

H. L. Flaugh, WX-DO

F. J. Edeskuty, WX-1

D. D. Schmidt, WX-1

W. O. Lunsford, WX-1

P. O. Box 1663

Los Alamos, NM 87544

31 Mason \& Hanger - Silas Mason Co., Inc.

Pantex Plant

Attn:

R. L Coffey, Tester Design

R. M. Loghry, General Manager

E. T. Collins, NES

J. E. Fulierton, NES

C. D. Alley, Director Prod \& Oper

J. E. Galloway, NES

D. J. Cole, Mfg Oper

A. D. Cornelius, Assy Eng

E. J. Parrish, Mfg Oper

J. C. Drummond, Quality

J. L. Peak, T\&DT

T. I. Folks, Pgm Mgmt

C. E. Green, Eng \& Design

T. F. Hall, ES\&H/WM

J. J. Henard, T\&DT

E. J. Henke, Pgm Mgmt

T. R. Jones, Assy Eng

M. A. Kelley, Tester Design

J. L. Loerwald, Quality

G. C. Moncivias. T\&DT

P. O. Box 300200

T. J. Morris, NES

E. E. Poore, T\&DT

D. J. Renteria, Eval Eng

C. D. Smith, Procurement

R. L. Spray, Eval Eng

L. D. Stoddard, Tooling

S. J. Ufford, Manufacturing

K. W. Wampler, Eval Eng

D. E. Whitson, Pgm Mgmt

R. L. Wieck, Exp Tech

J. C. Yarbrough, Assy Eng

Amarillo, TX 79177 


\section{Distribution (Continued)}

5

University of California

Lawrence Livermore National Laboratory

Attn: R. E. Clough, L-125

W. H. Hubbell, L-125

L. M. McGrew, L-125

N. A. Schneider, Jr., L-125

A. L. Scott, L-125

P. O. Box 808

Livermore, CA 94550

$\begin{array}{lll}1 & \text { MS9005 } & \text { J. B. Wright (Org. 5300) } \\ 1 & \text { MS9006 } & \text { E. E. Ives (Org. 5200) } \\ 1 & \text { MS9006 } & \text { D. J. Bohrer (Org. 5202) } \\ 1 & \text { MS9013 } & \text { A. C. Skinrood (Org. 5366) } \\ \text { 1 } & \text { MS9013 } & \text { D. R. Bozman (Org. 5366) } \\ 1 & \text { MS9013 } & \text { M. L. Foley (Org. 5366) } \\ 1 & \text { MS9013 } & \text { S. B. Johnson (Org. 5366) } \\ 1 & \text { MS9033 } & \text { C. A. Pura (Org. 5362) } \\ 1 & \text { MS9033 } & \text { G. E. Dietel (Org. 5362) } \\ 1 & \text { MS9033 } & \text { R. A. Pearson (Org. 5362) } \\ 1 & \text { MS9034 } & \text { W. J. Ghio (Org. 5363) } \\ 1 & \text { MS9203 } & \text { S. J. Vasey (Org. 5354) } \\ & & \\ 1 & \text { MS0429 } & \text { W. C. Nickell (Org. 5100) } \\ 1 & \text { MS0437 } & \text { K. W. Schuler (Org. 1562) } \\ 1 & \text { MS0447 } & \text { J. O. Harrison (Org. 5115) } \\ 1 & \text { MS0447 } & \text { H. T. Lehman (Org. 5115) } \\ 1 & \text { MS0447 } & \text { P. J. Salazar (Org. 5115) } \\ 1 & \text { MS0459 } & \text { C. C. Burks (Org. 5203) } \\ 1 & \text { MS0459 } & \text { T. S. Edrington (Org. 5205) } \\ 1 & \text { MS0461 } & \text { D. L. McCoy (Org. 5504) } \\ 1 & \text { MS0483 } & \text { J. P. Lopez (Org. 5104) } \\ 1 & \text { MS0490 } & \text { S. D. Spray (Org. 12331) } \\ 1 & \text { MS0490 } & \text { J.P. Hoffman. Jr. (Org. 12331) } \\ 1 & \text { MS0492 } & \text { D. H. Loescher (Org. 12332) } \\ 1 & \text { MS0492 } & \text { J. A. Richardson (Org. 12332) } \\ 1 & \text { MS0492 } & \text { D. A. Summers (Org. 12332) } \\ 1 & \text { MS0507 } & \text { R. A. David (Org. 2700) } \\ 1 & \text { MS0633 } & \text { J. J. Schwartz (Org. 12363) } \\ 1 & \text { MS0634 } & \text { W. H. Carroll. Jr. (Org. 12361) } \\ 1 & \text { MS0637 } & \text { E. M. Austin (Org. 12336) } \\ 1 & \text { MS0768 } & \text { J. W. Kane (Org. 5806) } \\ 1 & \text { MS0768 } & \text { C. L Schuster (Org. 5806) } \\ \text { I } & \text { MS0829 } & \text { E. M. Grose (Org. 12323) } \\ & & \end{array}$




\section{Distribution (Continued)}

1 MS0865 M. E. Morris (Org. 2753)

1 MS0865 J. R. Barnum (Org. 2753)

1 MS0865 K. C. Chen (Org. 2753)

1 MS0865 S. W. Holmes (Org. 2753)

3 MS0865 $\quad$ R. D. Jones (Org. 2753)

1 MS1058 P. A. Longmire (Org. 5407)

1 MS1058 R. W. Martin (Org. 5407)

1 MS1390 T. Frederiksen (Org. 12364-1)

1 MS1390 E. H. Morris (Org. 12364-2)

1 MS9018 Central Technical files (Org. 8523-2)

5 MS0899 Technical Library (Org. 7141)

1 MS0619 Technical Publications (Org. 7151)

2 MS1119 Document Processing for DOE/OSTI (Org. 7613-2) 


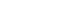

